\title{
Screening of a small, well-curated 'natural compound' library identifies two rotenoids with potent nematocidal activity against Haemonchus contortus
}

H. M. P. Dilrukshi Herath ${ }^{\mathrm{a}}$, Sarah Preston ${ }^{\mathrm{a}, \mathrm{b}}$, Andreas Hofmann ${ }^{\mathrm{a}, \mathrm{c}}$, Rohan A. Davis ${ }^{\mathrm{c}}$, Bill B.-C. Chang ${ }^{\text {a }}$, Abdul Jabbar ${ }^{\text {a }}$, Robin B. Gasser ${ }^{\text {a,* }}$

${ }^{a}$ Faculty of Veterinary and Agricultural Sciences, The University of Melbourne, Parkville, Victoria 3010, Australia

${ }^{\mathrm{b}}$ Faculty of Science and Technology, Federation University, Ballarat, Victoria 3350, Australia

c Griffith Institute for Drug Discovery, Griffith University, Don Young Road, Nathan, Queensland 4111, Australia

* Corresponding author. Tel: +613-97312283; fax: +613-97312366.

E-mail address: robinbg@unimelb.edu.au (R.B. Gasser) 


\section{ABSTRACT}

The control of parasitic roundworms (nematodes) is heavily reliant on the use of a limited number of anthelmintic drugs. However, drug resistance is now very widespread and no vaccines are available, such that the discovery of new chemical entities is crucial. Within this context, we screened a library of pure natural products $(n=400)$ against exsheathed third-stage (xL3) larvae of the parasitic nematode Haemonchus contortus using a whole-organism screening method. We identified two plantderived rotenoids, namely deguelin and rotenone, with inhibitory activity on xL3 motility. Whereas rotenone was not investigated further because of its toxicity to mammals/vertebrates, dose response and cytotoxicity studies of deguelin showed potent and selective inhibitory activity on motility of xL3 larvae of $H$. contortus. Detailed future work needs to be conducted to explore the mode of action of this compound on $H$. contortus and related nematodes and to assess its potential as an anthelmintic candidate.

Keywords:

Natural product

Rotenoid

Rotenone

Deguelin

Haemonchus contortus 


\section{Introduction}

Parasitic worms cause substantial mortality and morbidity in animals, and also major losses to animal and food production globally. Importantly, parasitic roundworms of the order Strongylida cause some of the most important diseases of livestock in Australia and worldwide, affecting hundreds of millions of food animals (including sheep, goats, cattle and pigs), with economic losses estimated at tens of billions of dollars per annum globally (Roeber et al., 2013; Lane et al., 2015). These pathogens cause gastritis, enteritis, anaemia and/or associated complications, and death in severely affected animals. All of these parasites are transmitted orally from contaminated pasture to the host through a direct life cycle (cf. Graem et al., 2014): eggs are excreted in host faeces; the first-stage larva (L1) develops inside the egg to then hatch (within 1 day) and develop through to the second- and third-stage larval stages (L2s and L3s) in about a week; the infective L3s are then ingested by the host, exsheath (xL3) and develop through fourth-stage larvae (Graem et al., 2014) to dioecious adults (within 3 weeks) in the gut of the animal.

Currently, the control of parasitic nematodes of livestock animals relies largely on the use of a limited number of anti-parasitic drugs. However, drug resistance is now very widespread (e.g., Kaplan and Vidyashankar, 2012) and no vaccines are available for the vast majority of these worms, such that the discovery of new drugs is critical, to ensure sustained and effective control into the future. Although the development of the compound monepantel (Kaminsky et al., 2008; Prichard and Geary, 2008) has provided fresh hope for the design of new classes of nematocides, success in identifying new drugs and drug targets using conventional screening approaches has been limited. Recent investigations of the genomes, transcriptomes and biology of a number of strongylid nematodes, including the barber's pole worm (Haemonchus contortus; Schwarz et al., 2013; Laing et al., 2013), hookworms (Necator americanus and Ancylostoma ceylanicum; Tang et al., 2014; Schwarz et al., 2015) and a nodule worm (Oesophagostomum dentatum; Tyagi et al. 2015), are revolutionizing the way we study these parasites, and can now support the discovery of new interventions. In collaboration with Compounds Australia (www.griffith.edu.au/science-aviation/compounds-australia), in the present study, we screened compounds from a small, well-curated library against parasitic stages of $H$. contortus (of ruminants), to identify any hit compounds, and then characterise and assess them as nematocide candidates.

\section{Materials and methods}

Third-stage (L3s) larvae of $H$. contortus (Haecon-5 strain; Schwarz et al., 2013) were cultured from the faeces from mono-specifically infected sheep as described previously (Preston et al., 2015, 2016). Approval to infect sheep was given by the University of Melbourne (animal ethics permit no. 1413429).

The natural product library was purchased from Compounds Australia (www.griffith.edu.au/science-aviation/compounds-australia). This open-access library was established in 2010 by R.A.D. and contained 400 distinct small molecules, the majority ( 55\%) of which had been purified from plants (Levrier et al., 2013), fungi (Davis, 2005) and marine invertebrates (Barnes et al., 2010). Approximately 30\% of this library contained semisynthetic natural product analogues (Barnes et al., 2016), while $15 \%$ were known drugs or synthetic compounds inspired by natural products. All compounds (purity: $>95 \%$ ) were supplied at a concentration of $5 \mathrm{mM}$ in dimethyl sulfoxide (DMSO; cat no. 2225; Ajax Finechem, Australia) and diluted to a concentration of $20 \mu \mathrm{M}$ of compound and $0.5 \%$ of DMSO in Luria Bertani (LB) medium, supplemented with $1 \%$ antibiotics-antimycotic mix (cat no. 15240-062; Gibco); this supplemented medium was designated LB* (cf. Preston et al., 2015). Test compounds were transferred using a multi-channel pipette (Finnpipette, Thermo Scientific, USA) into 96-well flat bottomed microplates (cat no. 3635; Corning 3650, Life Sciences, USA) in a volume of $50 \mu \mathrm{l}$. Test and the positive control compounds 
monepantel (Zolvix ${ }^{\circledR}$, Novartis Animal Health, Switzerland) and moxidectin (Cydectin ${ }^{\circledR}$, Virbac, France) were tested in triplicate on exsheathed L3s (xL3s) using established published methods (Preston et al., 2015, 2016). Negative controls, LB* and LB* + 0.5\% DMSO were tested in replicates of six. A volume of $50 \mu$ c containing 300 exsheathed L3 (xL3s) was then transferred into each well using a multi-channel pipette (Finnpipette, Thermo Scientific). Plates were incubated for $72 \mathrm{~h}$ at $38{ }^{\circ} \mathrm{C}$ and $10 \% \mathrm{CO}_{2}$, and monitored for movement as described previously (Preston et al., 2015, 2016). A compound was recorded as having anti$x L 3$ activity if it reduced motility by $\geq 70 \%$ at $72 \mathrm{~h}$. Compounds with anti-xL3 activity were screened twice at $20 \mu \mathrm{M}$ to verify their inhibitory properties on motility.

To determine the $50 \%$ inhibitory concentration ( $\mathrm{IC}_{50}$ values of (-)-deguelin (catalogue code: LX-350-118-M005, Enzo Life Sciences, Switzerland; purity: $\geq 95 \%$ ) on larval motility, this chemical was serially diluted two-fold in LB*, starting at a concentration of $100 \mu \mathrm{M}$, as described previously (Preston et al., 2015, 2016). The motility of xL3s was recorded $24 \mathrm{~h}, 48$ $\mathrm{h}$ and $72 \mathrm{~h}$ following exposure to the chemical (Preston et al., 2015, 2016). To establish $\mathrm{IC}_{50}$ values, compound concentrations were $\log _{10}$-transformed, and a variable slope four-parameter equation was used, constraining the top to $100 \%$ (Graphpad Prism, v7.01, USA). A two-way analysis of variance (ANOVA) and the Dunnett's multiple comparison test were used to compare the effects of compounds on motility at different concentrations and time points. All experiments were performed in triplicate on three separate days.

Human cell toxicity was assessed as described by Fisher et al. (2014). In brief, neonatal foreskin fibroblast cells (NFF) were cultured in RPMI 1640 medium (Life Technologies, Inc., Rockville, MD, USA) supplemented with $10 \%$ foetal calf serum (CSL Biosciences, Victoria, Australia) and 1\% streptomycin (Life Technologies Inc., USA). The inhibition of growth (\%) was compared with matched DMSO controls. IC $_{50}$ values were calculated using linear interpolation of inhibition curves. The mean $\mathrm{IC}_{50}$ value ( \pm standard deviation, SD) was recorded in three independent experiments, each carried out in triplicate wells. The selectivity index (SI) was calculated as $\mathrm{IC}_{50}$ for NFF divided by $\mathrm{IC}_{50}$ for $H$. contortus.

\section{Results and discussion}

From the in vitro primary screening of the 400 compounds against $H$. contortus, only rotenone and deguelin were found to reduce xL3 motility by $\geq 70 \%$. Both compounds were re-screened at $20 \mu \mathrm{M}$ and shown to consistently inhibit xL3 motility. IC ${ }_{50}$ values for deguelin as well as those of monepantel and moxidectin (positive controls) on xL3 motility were determined at $24 \mathrm{~h}, 48 \mathrm{~h}$ and $72 \mathrm{~h}$ and then compared. The monepantel and moxidectin control compounds were more effective, under the current conditions, than deguelin at inhibiting xL3s after $72 \mathrm{~h}$, with $\mathrm{IC}_{50}$ values of $0.13 \pm 0.10 \mu \mathrm{M}, 0.04 \pm 0.01 \mu \mathrm{M}$ and $19.13 \pm 5.71 \mu \mathrm{M}$ respectively (Fig. 1; Table 1). In addition, deguelin was found to have low toxicity against human NFFs using a cell proliferation assay $\left(\mathrm{IC}_{50}>50 \mu \mathrm{M}\right)$ with a 2.6-fold selectivity for $H$. contortus.

Given the substantial problems linked to anthelmintic resistance in parasitic worms of livestock animals, a continued effort is needed to search for new and effective chemicals for development and commercialisation, particularly if they have new modes of action compared with existing drugs (Epe and Kaminsky, 2013). There has been a renewed interest in pursuing natural products for drug discovery (Shen, 2015) because of the biologically relevant chemical diversity of such products and because they are aligned with Nature's need to develop a "chemical warfare” arsenal (Baell, 2016).

Here, we screened a small set of natural compounds $(n=400)$ against Haemonchus contortus, the barber's pole worm, and identified rotenone and deguelin to have an activity against this worm in vitro. These two flavonoids originate from plants of the family Leguminosae (e.g., Wenjie et al., 2009; Chen et al., 2014; Vats and Kamal, 2014) and have been shown to possess drug-like properties. For instance, deguelin has been reported to affect 
some cancers (of lung, stomach and prostate) (Gerhauser et al., 1997; Udeani et al., 1997; Lee et al., 2005; Aruldmpalam et al., 2011; Boreddy and Srivastava, 2013; Farmer et al., 2013; Shang et al., 2014), and has anti-inflammatory, anti-angiogenic and apoptotic effects (Lee, 2004; Paulus et al., 2012). In addition, rotenoids extracted from plants such as Derris elliptica (Tuba plant), D. involuta (Jewel vine), Lonchocarpus utilis (Cub) or L. urucu (Barbasco) have been used as natural acaricides or insecticides (e.g., Ashack et al., 1980; Embeya et al., 2014). As rotenone is lethal to fishes but not to mammals to the same extent (Isman, 2006), there would be considerable concerns about its use as a parasiticide. Due to toxicity concerns, we did not pursue this chemical further in the present study. As deguelin is chemically related to rotenone, there was some initial concern about the safety of deguelin in vertebrates (Caboni et al., 2004). In contrast, although Parkinson's disease-like signs have been reported in mice upon chronic administration of deguelin (6 mg/kg/day) (Caboni et al., 2004), there is no evidence that deguelin exhibits toxic effects in mice or rats at $2-5 \mathrm{mg} / \mathrm{kg}$ (therapeutic doses; Udeani et al., 2001; Lee et al., 2005; Boreddy and Srivastava, 2013; Mehta et al., 2013). Moreover, deguelin and analogues thereof have been explored and assessed as anti-cancer drugs (Udeani et al., 1997; Murillo et al., 2002; Lee et al., 2016), but further work needs to be conducted to verify toxicity of various analogues to mammalian cells.

Evidence indicates that deguelin exerts its effect(s) on rapidly replicating cells (e.g., cancer cells) via extracellular signal-regulated kinase (ERK) and phosphatidylinositol 3-kinase (PI3K)/AkT (Bortul et al., 2005; Mehta et al., 2013, Wu et al., 2016), insulin-like growth factor receptor (Kim et al., 2008; Suh et al., 2013; Lee et al., 2015) and/or the glycogen synthase kinase-3 $\beta / \beta$-catenin (Thamilselvan et al., 2011) signaling pathways. Deguelin has been reported to decrease tumor growth and metastasis in rodents via the induction of apoptosis and the inhibition of epithelial-to-mesenchymal transition by targeting the nuclear factor-kappa beta (NF-kB) and tumour growth factor- $\beta 1$ (TGF- $\beta 1)$ pathways (Boreddy and Srivastava, 2013; Liu et al., 2016). Biochemically, deguelin has been shown to reduce oxygen consumption via a down-regulation of mitochondrial electron transport and/or phorbol esterinduced ornithine decarboxylase (Gerhauser et al, 1997; Fang and Casida, 1998; Garcia et al., 2012; Vrana et al., 2013). In contrast, nothing is known about how deguelin affects parasitic nematodes. Therefore, we plan to explore the molecular differences between deguelin-treated and untreated $H$. contortus using transcriptomic and/or biochemical approaches, aiming at a better understanding of how this chemical affects biological pathways in this parasitic nematode. The relative safety of deguelin in mammals at therapeutic doses (Udeani et al., 2001; Lee et al., 2005; Boreddy and Srivastava, 2013; Mehta et al., 2013), the amenability of its chemical scaffold to chemical synthesis in order to generate new analogs and assess toxic properties (Kim et al., 2008; Chang et al., 2012; Lee et al., 2016) and the potency of deguelin against $H$. contortus observed in the present study set the scene for future investigations of deguelin and its derivatives in nematodes.

\section{Acknowledgements}

The present study was funded by the Australian Research Council (ARC), Yourgene Bioscience (Taiwan) and The University of Melbourne (RBG). ARC played no role in the design of the study or collection, analysis or interpretation of data, or in the writing of the manuscript. The authors thank Compounds Australia (www.griffith.edu.au/scienceaviation/compounds-australia) for access to the Davis open-access natural product library, which forms part of the Open Access Compound Collection. 


\section{References}

Arulampalam, V., Kolosenko, I., Hjortsberg, L., Bjorklund, A., Grander, D., Tamm, K.P., 2011. Activation of STAT1 is required for interferon-alpha-mediated cell death. Exp. Cell. Res. 317, 9-19. doi.org/10.1016/j.yexcr.2010.10.002.

Ashack, R.J., McCarty, L.P., Malek, R.S., Goodman, F.R., Norton, P.P., 1980. Evaluation of rotenone and related compounds as antagonists of slow-reacting substance of anaphylaxis. J. Med. Chem. 9, 1022-1026. doi: 10.1021/jm00183a011.

Baell, J.B., 2016. Feeling nature's pains: Natural products, natural product drugs, and pan assay interference compounds (PAINs). J. Nat. Prod. 79, 616-28. doi: 10.1021/acs.jnatprod.5b00947.

Barnes, E.C., Kumar, R., Davis, R.A., 2016. The use of isolated natural products as scaffolds for the generation of chemically diverse screening libraries for drug discovery. Nat. Prod. Rep. 33, 372-381. doi:10.1039/C5NP00121H.

Barnes, E.C., Said, N.A.B.M., Williams, E.D., Hooper, J.N.A., Davis, R.A., 2010. Ecionines A and B, two new cytotoxic pyridoacridine alkaloids from the Australian marine sponge, Ecionemia geodides. Tetrahed geodides. Tetrahedron. 66, 283-287. doi:org/10.1016/j.tet.2009.10.109.

Boreddy, S.R., Srivastava, S.K., 2013. Deguelin suppresses pancreatic tumor growth and metastasis by inhibiting epithelial to mesenchymal transition in an orthotopic model. Oncogene 32, 39803991. doi:10.1038/onc.2012.413.

Bortul, R., Tazzari, P.L., Billi, A.M., Tabellini, G., Mantovani, I., Cappellini, A., Grafone, T., Martinelli, G., Conte, R., Martelli, A.M., 2005. Deguelin, a PI3K/AKT inhibitor, enhances chemosensitivity of leukaemia cells with an active PI3K/AKT pathway. Brit. J. Haematol. 129, 677-686. doi:10.1111/j.1365-2141.2005.05504.x.

Caboni, P., Sherer, T.B., Zhang, N., Taylor, G., Na, H.M., Greenamyre, J.T., Casida, J.E., 2004. Rotenone, deguelin, their metabolites, and the rat model of Parkinson's disease. Chem. Res. Toxicol. 17, 1540-1548. doi:10.1021/tx049867r.

Chang, D.J., An, H., Kim, K.S., Kim, H.H., Jung, J., Lee, J.M., Kim, N.J., Han, Y.T., Yun, H., Lee, S., Lee, G., Lee, S., Lee, J.S., Cha, J.H., Park, J.H., Park, J.W., Lee, S.C., Kim, S.G., Kim, J.H., Lee, H.Y., Kim, K.W., Suh, Y.G., 2012. Design, synthesis, and biological evaluation of novel deguelin-based heat shock protein 90 (HSP90) inhibitors targeting proliferation and angiogenesis. J. Med. Chem. 27, 10863-10884. doi: 10.1021/jm301488q.

Chen, C.S., Ho, D.R., Chen, F.Y., Chen, C.R., Ke, Y.D., Su, J.G.J., 2014. AKT mediates actinomycin D-induced p53 expression. Oncotarget 5, 693-703. doi.10.18632/oncotarget.1328.

Davis, R.A., 2005. Isolation and structure elucidation of the new fungal metabolite (-)-xylariamide A. J. Nat. Prod. 68, 769-772. doi.org/10.1016/j.bmcl.2008.03.090.

Embeya, O.V., Simbi, J.B.L., Stevigny, C., Vandenput, S., Shongo, P.C., Duez, P., 2014. Traditional plant-based remedies to control gastrointestinal disorders in livestock in the regions of Kamina and Kaniama (Katanga province, Democratic Republic of Congo). J. Ethnopharmacol. 153, 686-93. doi.org/10.1016/j.jep.2014.03.027.

Epe, C., Kaminsky, R., 2013. New advancement in anthelmintic drugs in veterinary medicine. Trends Parasitol. 29, 129-134. doi:10.1016/j.pt.2013.01.001.

Fang, N., Casida, J.E., 1998. Anticancer action of cubé insecticide: Correlation for rotenoid constituents between inhibition of NADH:ubiquinone oxidoreductase and induced ornithine decarboxylase activities. Proc. Natl. Acad. Sci. U.S.A. 95, 3380-3384.

Farmer, R.L., Scheidt, K.A., 2013. A concise enantioselective synthesis and cytotoxic evaluation of the anticancer rotenoid deguelin enabled by a tandem knoevenagel/conjugate addition/decarboxylation sequence. Chem. Sci. 4, 3304-3309. doi:10.1039/C3SC50424G.

Fisher, G.M., Tanpure, R.P., Douchez, A., Andrews, K.T., Poulsen, S.A., 2014. Synthesis and evaluation of antimalarial properties of novel 4-aminoquinoline hybrid compounds. Chem. Biol. Drug Des. 84, 462-472. doi:10.1111/cbdd.12335.

Garcia, J., Barluenga, S., Gorska, K., Sasse, F., Winssinger, N., 2012. Synthesis of deguelin-biotin conjugates and investigation into deguelin's interactions. Bioorg. Med. Chem. 20, 672-680. dx.doi.org/10.1016/j.bmc.2011.09.064.

Gerhauser, C, Lee, S.K., Kosmeder, J.W., Moriarty, R.M., Hamel, E., Mehta, R.G., Moon, R.C., Pezzuto, J.M., 1997. Regulation of ornithine decarboxylase induction by deguelin, a natural product cancer chemopreventive agent. Cancer Res. 57, 3429-3435. 
Graem, B., Coleman, G., Constantinoiu, C., Gasser, R., Holyoake, P., Hobbs, R., Lymbery, A., O’Handley, R., Phalen, D., Pomroy, W., Rothwell, J., Sangster, N., Slapeta, J., Thompson, A., Traub, R., Woodgate, R., 2014. Australian animal parasites-inside and out. Ed. Beveridge, I and Emery, D., The Australian Society for Parasitology Inc: Australia. pp 8-19.

Isman, M.B., 2006. Botanical insecticides, deterrents, and repellents in modern agriculture and an increasingly regulated world. Annu. Rev. Entomol. 51, 45-66. doi: 10.1146/annurev.ento.51.110104.151146.

Kaminsky, R., Gauvry, N., Weber, S.S., Skripsky, T., Bouvier, J., Wenger, A., Schroeder, F., Desaules, Y., Hotz, R., Goebel, T., 2008. Identification of the amino-acetonitrile derivative monepantel (AAD 1566) as a new anthelmintic drug development candidate. Parasitol. Res. 103, 931-939. doi: 10.1007/s00436-008-1080-7.

Kaplan, R.M., Vidyashankar, A.N., 2012. An inconvenient truth: global worming and anthelmintic resistance. Vet. Parasitol. 186., 70-78. doi:10.1016/j.vetpar.2011.11.048.

Kim, W.Y., Chang, D.J., Hennessy, B., Kang, H.J., Yoo, J., Han, S.H., Kim, Y.S., Park, H.J., Seo, S.Y., Mills, G., Kim, K.W., Hong, W.K., Suh, Y.G., Lee, H.Y., 2008. A novel derivative of the natural agent deguelin for cancer chemoprevention and therapy. Cancer Prev. Res. (Phila). 1, 577-587. doi:10.1158/1940-6207.CAPR-08-0184.

Laing, R., Kikuchi, T., Martinelli, A., Tsai, I.J., Beech, R.N., Redman, E., Holroyd, N., Bartley, D.J., Beasley, H., Britton, C., Curran, D., Devaney, E., Gilabert, A., Hunt, M., Jackson, F., Johnston, S.L., Kryukov, I., Li, K., Morrison, A.A., Reid, A.J., Sargison, N., Saunders, G.I., Wasmuth, J.D., Wolstenholme, A., Berriman, M., Gilleard, J.S., Cotton, J.A., 2013. The genome and transcriptome of Haemonchus contortus, a key model parasite for drug and vaccine discovery. Genome Biol. 14, R88. doi: 10.1186/gb-2013-14-8-r88.

Lane, J., Jubb, T., Shepherd, R., Webb-Ware, J., Fordyce, G., 2015. Priority list of endemic diseases for the red meat industries. Final Report. B.AHE.0010. Meat \& Livestock Australia Limited. ISBN XXXXXX.

Lee, H.Y., 2004. Molecular mechanisms of deguelin-induced apoptosis in transformed human bronchial epithelial cells. Biochem. Pharmacol. 68, 119-1124. dx.doi.org/10.1016/j.bcp.2004.05.033.

Lee, H.Y., Oh, S.H., Woo, J.K., Kim, W.Y., Van Pelt, C.S., Price, R.E., Cody, D., Tran, H., Pezzuto, J.M., Moriarty, R.M., Hong, W.K., 2005. Chemopreventive effects of deguelin, a novel Akt inhibitor, on tobacco-induced lung tumorigenesis. J. Natl. Cancer Inst. 97, 1695-1699. doi.org/10.1093/jnci/dji377.

Lee, S.C., Min, H.Y., Choi, H., Kim, H.S., Kim, K.C., Park, S.J., Seong, M.A., Seo, J.H., Park, H.J., Suh, Y.G., Kim, K.W., Hong, H.S., Kim, H., Lee, M.Y., Lee, J., Lee, H.Y., 2015. Synthesis and evaluation of a novel deguelin derivative, L80, which disrupts ATP binding to the Cterminal domain of heat shock protein 90. Mol. Pharmacol. 88, 245-55. doi:10.1124/mol.114.096883.

Lee, S.C., Min, H.Y., Choi, H., Bae, S.Y., Park, K.H., Hyun, S.Y., Lee, H.J., Moon, J., Park, S.H., Kim, J.Y., An, H., Park, S.J., Seo, J.H., Lee, S., Kim, Y.M., Park, H.J., Lee, S.K., Lee, J., Lee, J., Kim, K.W., Suh, Y.G., Lee, H.Y., 2016. Deguelin analogue SH-1242 inhibits Hsp90 activity and exerts potent anticancer efficacy with limited neurotoxicity. Cancer Res. 76, 68699. doi:10.1158/0008-5472.CAN-15-1492.

Levrier, C., Balastrier, M., Beattie, K.D., Carroll, A.R., Martin, F., Choomuenwai, V., Davis, R.A., 2013. Pyridocoumarin, aristolactam and aporphine alkaloids from the Australian rainforest plant Goniothalamu australis. Phytochemistry 86, 121-126. doi: 10.1016/j.phytochem.2012.09.019.

Liu, Y.P., Lee, J.J., Lai, T.C., Lee, C.H., Hsiao, Y.W., Chen, P.S., Liu, W.T., Hong, C.Y., Lin, S.K., Ping Kuo, M.Y., Lu, P.J., Hsiao, M., 2016. Suppressive function of low-dose deguelin on the invasion of oral cancer cells by downregulating tumor necrosis factor alpha-induced nuclear factor-kappa B signaling. Head Neck 38, E524-34. doi:10.1002/hed.24034.

Mehta, R., Katta, H., Alimirah, F., Patel, R., Murillo, G., Peng, X., Muzzio, M., Mehta, R.G., 2013. Deguelin action involves c-Met and EGFR signaling pathways in triple negative breast cancer cells. PLoS ONE 8, e65113. doi:10.1371/journal.pone.0065113.

Murillo, G., Salti, G.I., Kosmeder, J.W II., Pezzuto, J.M., Mehta, R.G., 2002. Deguelin inhibits the growth of colon cancer cells through the induction of apoptosis and cell cycle arrest. Eur. J. Cancer 38, 2446-2454. doi.org/10.1016/S0959-8049(02)00192-2. 
Paulus, P., Ockelmann, P., Tacke, S., Karnowski, N., Ellinghaus, P., Scheller, B., Holfeld, J., Urbschat, A., Zacharowski, K., 2012. Deguelin attenuates reperfusion injury and improves outcome after orthotopic lung transplantation in the rat. PLoS ONE 7, e39265. doi:10.1371/journal.pone.0039265.

Preston, S., Jabbar, A., Nowell, C., Joachim, A., Ruttkowski, B., Baell, J., Cardno, T., Korhonen, P.K., Piedrafita, D., Ansell, B.R.E., Jex, A.R., Hofmann, A., Gasser, R.B., 2015. Low cost whole-organism screening of compounds for anthelmintic activity. Int. J. Parasitol. 45, 333343.

Preston, S., Jabbar, A., Nowell, C., Joachim, A., Ruttkowski, B., Cardno, T., Hofmann, A., Gasser, R.B., 2016. Practical and low cost whole-organism motility assay: a step-by-step protocol. Mol. Cell. Probes 30, 13-17. doi:10.1016/j.mcp.2015.08.005.

Prichard, R.K., Geary, T.G., 2008. Drug discovery: fresh hope to can the worms. Nature 452, 157-158. doi:10.1038/452157a.

Roeber, F., Jex, A.R., Gasser, R.B., 2013. Impact of gastrointestinal parasitic nematodes of sheep, and the role of advanced molecular tools for exploring epidemiology and drug resistance-an Australian perspective. Parasit. Vectors 6, 153, 1-12. doi: 10.1186/1756-3305-6-327.

Schwarz, E.M., Hu, Y., Antoshechkin, I., Miller, M.M., Sternberg, P.W., Aroian, R.V., 2015. The genome and transcriptome of the zoonotic hookworm Ancylostoma ceylanicum identify infection-specific gene families. Nature Genet. 47, 416-422. doi:10.1038/ng.3237.

Schwarz, E.M., Korhonen, P.K., Campbell, B.E., Young, N.D., Jex, A.R., Jabbar, A., Hall, R.S., Mondal, A., Howe, A.C., Pell, J., Hofmann, A., Boag, P.R., Zhu, X.Q., Gregory, T.R., Loukas, A., Williams, B.A., Antoshechkin, I., Brown, C.T., Sternberg, P.W., Gasser, R.B., 2013. The genome and developmental transcriptome of the strongylid nematode Haemonchus contortus. Genome Biol. 14. doi:10.1186/gb-2013-14-8-r88.

Shang, H.S., Chang, J.B., Lin, J.H., Lin, J.P., Hsu, S.C., Liu, C.M., Liu, J.Y., Wu, P.P., Lu, H.F., Au, M.K., Chung, J.G., 2014. Deguelin inhibits the migration and invasion of U-2 OS human osteosarcoma cells via the inhibition of matrix metalloproteinase-2/-9 in vitro. Molecules. 19, 16588-16608. doi: 10.3390/molecules191016588.

Shen, B., 2015. A new golden age of natural products drug discovery. Cell. 163, 1297-1300. doi.org/10.1016/j.cell.2015.11.031.

Suh, Y.A., Kim, J.H., Sung, M.A., Boo, H.J., Yun, H.J., Lee, S.H., Lee, H.J., Min, H.Y., Suh, Y.G., Kim, K.W., Lee, H.Y., 2013. A novel antitumor activity of deguelin targeting the insulin-like growth factor (IGF) receptor pathway via up-regulation of IGF-binding protein-3 expression in breast cancer. Cancer Lett. 332, 102-109. doi:10.1016/j.canlet.2013.01.022.

Tang, Y.T., Gao, X., Rosa, B.A., Abubucker, S., Hallsworth-Pepin, K., Martin, J., Tyagi, R., Heizer, E., Zhang, X., Bhonagiri-Palsikar, V., 2014. Genome of the human hookworm Necator americanus. Nature Genet. 46, 261-269. doi:10.1038/ng.2875.

Thamilselvan, V., Menon, M., Thamilselvan, S., 2011. Anticancer efficacy of deguelin in human prostate cancer cells targeting glycogen synthase kinase-3 $\beta / \beta$-catenin pathway. Int. J. Cancer. 15, 2916-2927. doi:10.1002/ijc.25949.

Tyagi, R., Joachim, A., Ruttkowski, B., Rosa, B.A., Martin, J.C., Hallsworth-Pepin, K., Zhang, X., Ozersky, P., Wilson, R.K., Ranganathan, S., 2015. Cracking the nodule worm code advances knowledge of parasite biology and biotechnology to tackle major diseases of livestock. Biotechnol. Adv. 33, 980-991. doi.org/10.1016/j.biotechadv.2015.05.004.

Udeani, G.O., Zhao, G.M., Shin, Y.G., Kosmeder, J.W.II., Beecher, C.W., Kinghorn, A.D., Moriarty, R.M., Moon, R.C., Pezzuto, J.M., 2001. Pharmacokinetics of deguelin, a cancer chemopreventive agent in rats. Chemother. Pharmacol. 47, 263-268. doi:10. $1007 / \mathrm{s} 002800000187$.

Udeani, G.O., Gerhauser, C., Thomas, C.F., Moon, R.C., Kosmeder, J.W., Kinghorn, A.D., Moriarty, R.M., Pezzuto, J.M., 1997. Cancer chemopreventive activity mediated by deguelin, a naturally occurring rotenoid. Cancer Res. 57, 3424-3428.

Vats, S., Kamal, R., 2014. Cassia occidentalis L. (a new source of rotenoids): its in vitro regulation by feeding precursors and larvicidal efficacy. Plant Cell Tiss. Organ Cult. 116, 403-409. doi 10.1007/s11240-013-0409-9.

Vrana, J.A., Boggs, N., Currie, H.N., Boyd, J., 2013. Amelioration of an undesired action of deguelin. Toxicon 74, 83-91. doi: 10.1016/j.toxicon.2013.07.028. 
Wenjie, J., Yuchun, F., Chunji, G., Yunhui, W., Pang, J., 2009. Extraction and purification of deguelin from Derris trifoliata Lour root. Int. J. Agric. Biol. Eng. 2, 98-103. doi: 10.3965/j.issn.19346344.2009.04.098-103.

Wu, W., Hai, Y., Chen, L., Liu, R.J., Han, Y.X., Li, W.H., Li, S., Lin, S., Wu, X.R., 2016. Deguelininduced blockade of PI3K/protein kinase B/MAP kinase signaling in zebrafish and breast cancer cell lines is mediated by down-regulation of fibroblast growth factor receptor 4 activity. Pharmacol. Res. Perspect. 4, e00212. doi: 10.1002/prp2.212. 
Fig. 1. Dose response curves showing the activity of deguelin (triangle) on the exsheathed third-stage larvae (xL3) of Haemonchus contortus compared with reference compounds monepantel (circle) and moxidectin (square) following 24 h, 48 h and 72 of incubation with the compound.

ah: the plots might be easier to read if different colours were used for the three different compounds (symbols and fitted lines). The x-axis title should be " $\log _{10}$ concentration" (no units). Is the scaling on the $\mathrm{x}$-axis correct? If monepantel has an $\mathrm{IC}_{50}$ of $0.13 \mu \mathrm{M}=0.13 \cdot 10^{-6}$ $\mathrm{M}$, then the $\log$ value should be $\log _{10}\left[0.13 \cdot 10^{-6} \mathrm{M} /(1 \mathrm{M})\right]=-6.9$. In the graph it looks more like -0.5 at $24 \mathrm{~h}$. 
Table 1. In vitro-activity of deguelin compared with that of monepantel or moxidectin on inhibition of xL3 motility after $72 \mathrm{~h}$ and cytotoxicity data.

\begin{tabular}{|c|c|c|c|c|c|c|c|}
\hline \multirow[t]{2}{*}{ Compound } & \multicolumn{6}{|c|}{ Lipinski rule-of-five $^{\mathrm{a}}$} & \multirow{2}{*}{$\begin{array}{l}\text { xL3 } M_{i} \\
\text { IC }_{50}(\mu M)\end{array}$} \\
\hline & 1 & 2 & 3 & 4 & 5 & 6 & \\
\hline Deguelin & 394.4 & 3.57 & 63.2 & 6 & 0 & 0 & $19.13 \pm 5.71$ \\
\hline
\end{tabular}

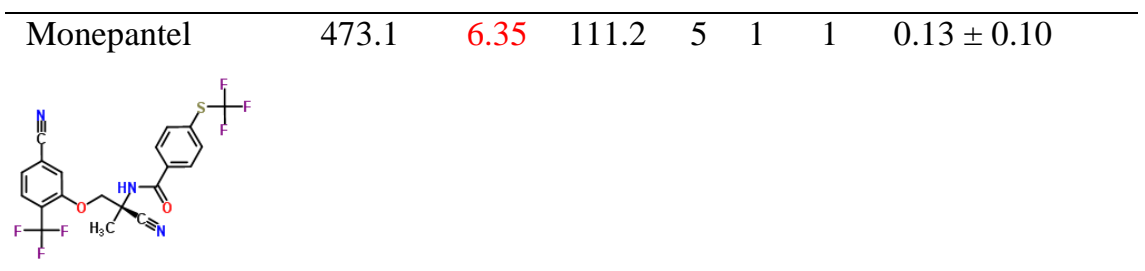

\begin{tabular}{llllllll}
\hline Moxidectin & 639.8 & 5.03 & 116.0 & 9 & 2 & 1 & $0.04 \pm 0.01$
\end{tabular}

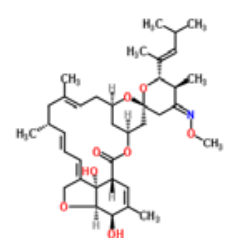

\footnotetext{
${ }^{\mathrm{a}}$ Lipinski rule-of-five: 1 = molecular weight (g/ mol); 2 = lipophilicity; 3 = polar surface area; 4 = H-bond acceptors; 5 = H-bond donors; 6 = number of rule of five violations; na $=$ not applicable. ah: perhaps one could highlight the violating features in red. Moxidectin has only 1 Ro5 violation; Lipinski allows up to $10 \mathrm{H}$-bond acceptors.
} 